\title{
Electrically conducting probes with full tungsten cantilever and tip for scanning probe applications
}

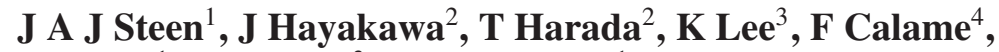 \\ G Boero ${ }^{1}$, A J Kulik ${ }^{3}$ and J Brugger ${ }^{1}$ \\ ${ }^{1}$ Microsystems Laboratory, Institute of Microelectronics and Microsystems, \\ Ecole Polytechnique Fédérale de Lausanne, 1015 Lausanne, Switzerland \\ ${ }^{2}$ Advanced Research Laboratory, Hitachi Ltd, Ibaraki, Japan \\ ${ }^{3}$ Institute of Physics of Complex Matter, Ecole Polytechnique Fédérale de Lausanne, \\ 1015 Lausanne, Switzerland \\ ${ }^{4}$ Ceramics Laboratory, Engineering Faculty, Ecole Polytechnique Fédérale de Lausanne, \\ 1015 Lausanne, Switzerland
}

E-mail: jeroen.steen@epfl.ch and juergen.brugger@epfl.ch

Received 30 November 2005, in final form 18 January 2006

Published 16 February 2006

Online at stacks.iop.org/Nano/17/1464

\begin{abstract}
We have developed a new hybrid AFM probe combining an SU-8 polymer body with a full tungsten cantilever having a nanometric tip. The fabrication is based on surface micromachining a silicon wafer, where tungsten is sputter deposited in oxidation sharpened moulds to yield sharp tips with radius below $20 \mathrm{~nm}$. The material properties of tungsten were measured, yielding a hardness of $14 \mathrm{GPa}$, a specific resistivity of $14.8 \mu \Omega \mathrm{cm}$ and Young's modulus of $380 \mathrm{GPa}$. Analyses of the probes show a mechanical quality factor of 90 in air, and a low contact resistance of $25 \Omega$ on a gold sample is measured. AFM imaging is demonstrated. As a step in the development of a robust electrically conducting AFM probe, the results are very promising.
\end{abstract}

(Some figures in this article are in colour only in the electronic version)

\section{Introduction}

Since the invention of the AFM in 1986 [1], only a very few alternatives to silicon $(\mathrm{Si})$ [2-4] or silicon nitride ( $\mathrm{SiN})[5,6]$ AFM-cantilevers/tips have been introduced. Some alternatives include (boron (B)-doped) diamond like carbon (DLC) [7-9], nickel (Ni) [10, 11], GaAs [12] and SU-8 [13]. Examples where the tip and the cantilever material differ are $\mathrm{Si}_{x} \mathrm{~N}_{y}$ cantilever with Si tip [14, 15], Si cantilever with focused ion beam (FIB) modified tungsten (W) tip [16], Ni cantilever with B-doped DLC tip [17] and quartz resonators with attached metal tips [18, 19]. Examples of applications requiring electrically conducting AFM probes, such as electrical analysis in contact mode or non contact mode, like Kelvin probe microscopy (KPM), demand better suited probes than currently available commercial varieties. Most often, these are Si probes coated with metal or B-doped DLC. Several drawbacks are apparent: first, coating a probe results in loss of tip sharpness, which reduces the resolution obtained in operation. Second, metal coated probes with a typical coating's thickness of around 20-25 nm quickly lose their coating upon a tip crash, wear, or melting at high current densities [20]. Although the wear properties of B-doped DLC (coated) tips are excellent, they exhibit a high contact resistance of $\sim 4 \mathrm{k} \Omega$ (compared to $\sim 100 \Omega$ for $\mathrm{Pt} /$ iridium coated tips) and display $I V$ characteristics that are not ohmic [20]. Due to the DLC CVD fabrication process the outer tip shape has a granular structure, which is inconvenient in KPM. To overcome these problems and make an important advance in the field, we aim for the development of AFM probes with full metal tip and cantilever. The ideal tip must be wear resistant, highly electrically conductive, inert, and exhibit a high melting temperature while maintaining high resolution imaging possibilities. Here, we present the fabrication and analysis of a hybrid AFM probe, with full $\mathrm{W}$ cantilever and tip, and photopolymer SU-8 body. $\mathrm{W}$ is known for its hardness, reported to be between 14 and $18 \mathrm{GPa}$ for a thin film $[21,22]$, high melting temperature $\left(3410^{\circ} \mathrm{C}\right)$ [23], and is widely used in scanning tunnelling 
Electrically conducting probes with full tungsten cantilever and tip for scanning probe applications

a)

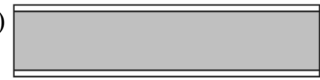

b)

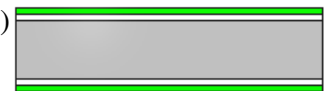

c)
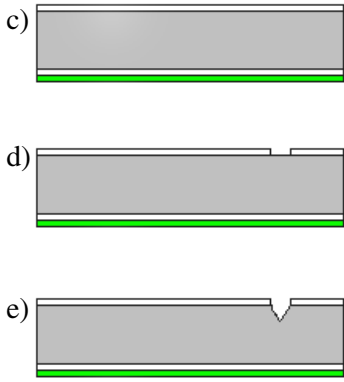

f)
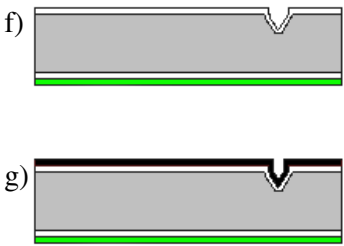

j)
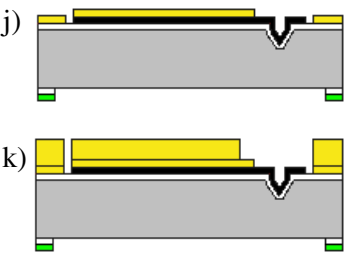

1)

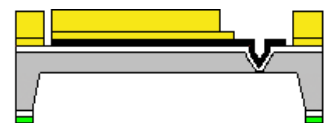

$\mathrm{m}$
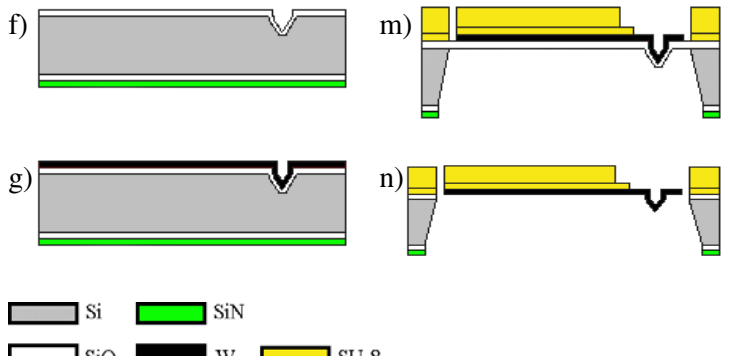

Figure 1. Fabrication process of a hybrid AFM probe with full $\mathrm{W}$ tip and cantilever: (a) wet oxidation of $\mathrm{Si}$ wafer, (b) LPCVD of $\mathrm{Si}_{3} \mathrm{~N}_{4}$, (c) topside removal of $\mathrm{Si}_{3} \mathrm{~N}_{4}$, (d) $\mathrm{SiO}_{2}$ dry etch, (e) $\mathrm{KOH}$ etch, (f) oxidation sharpening, (g) W sputtering, (h) $\mathrm{Si}_{3} \mathrm{~N}_{4}$ and $\mathrm{SiO}_{2}$ backside etch, (i) W dry etch, (j) $10 \mu \mathrm{m} \mathrm{SU}-8$, (k) $200 \mu \mathrm{m} \mathrm{SU}-8$, (1) $\mathrm{Si}$ wet etch $(\mathrm{KOH}),(\mathrm{m}) \mathrm{Si}$ dry etch, (n) $\mathrm{BHF} \mathrm{SiO}_{2}$ etch.

microscopy. Our surface micromachining technique uses a Si wafer as a template in which oxidation sharpened moulds [24] with a radius smaller than $20 \mathrm{~nm}$ are created for nanotip definition. FIB sharpening of $\mathrm{W}$ tips can give tips with a radius below $5 \mathrm{~nm}[16,18]$, but is rather time-consuming and expensive; our solution gives probes on a wafer scale and hence is commercially viable. After the mould fabrication, $\mathrm{W}$ is then sputter-deposited on the template, filling the moulds down to the bottom due to the good step coverage characteristics of the sputtering process. The body of the probe consists of a lithographically defined high aspect ratio polymer SU8 [25], resulting in a hybrid probe: a metallic cantilever with integrated tip and plastic body. Release of the probes is realized by a backside wet etch followed by a dry etch opening technique, after which they are analysed. The fabrication technique is versatile and can be extended to other metals in addition to $\mathrm{W}$.

\section{Experimental details}

As mentioned in the previous section, a surface micromachining technique is used to fabricate the hybrid AFM probes. A $100 \mathrm{~mm}$ (100)Si wafer with a thickness of $380 \mu \mathrm{m}$ serves as a template. After a $500 \mathrm{~nm}$ wet-oxidation at $1050^{\circ} \mathrm{C}$, a $500 \mathrm{~nm}$ thick LPCVD-layer of stoichiometric silicon nitride $\left(\mathrm{Si}_{3} \mathrm{~N}_{4}\right)$ was subsequently deposited on the wafer in a Centrotherm tube furnace (figures 1(a) and (b)). The $\mathrm{Si}_{3} \mathrm{~N}_{4}$ layer was then removed from the topside with $20 \mathrm{sccm} \mathrm{C}_{2} \mathrm{~F}_{6}$ plasma at $1800 \mathrm{~W}$ and $125 \mathrm{~V}$ substrate bias in an Alcatel 601E ICP etcher (figure 1(c)). On the backside the $\mathrm{Si}_{3} \mathrm{~N}_{4}$ was kept to serve as an etch mask for a backside etch in a potassium hydroxide $(\mathrm{KOH})$ solution in a subsequent process step. After photolithography and a subsequent dry etch of the $\mathrm{SiO}_{2}$ (using the same recipe as for the $\mathrm{Si}_{3} \mathrm{~N}_{4}$ etch), pyramidal holes were etched in a $40 \%$ $\mathrm{KOH}$ solution at $60^{\circ} \mathrm{C}$ for the tip-mould definition (figures 1 (d) and (e)). Then the remaining $\mathrm{SiO}_{2}$ was removed in buffered hydrofluoric acid (BHF). In order to enhance the mould sharpness a wet-oxidation sharpening step was carried out at $950^{\circ} \mathrm{C}$ [24] to grow $500 \mathrm{~nm} \mathrm{SiO}_{2}$ (figure 1(f)). This oxide layer also serves as an etch stop later in the process during a backside etch. In the next step, $500 \mathrm{~nm}$ of W was deposited with a DC sputtering process (BAS 450) at $5 \mathrm{~W} \mathrm{~cm}^{-2}$ at $300^{\circ} \mathrm{C}$. Prior to the sputtering, an extensive pre-sputtering was done to remove any unwanted $\mathrm{W}_{x} \mathrm{O}$ compound from the target [26]. A liquid nitrogen trap was used to trap water present in the chamber, maintaining a background pressure of $2 \times 10^{-5} \mathrm{~Pa}$. The deposition was carried out in argon at $0.6 \mathrm{~Pa}$ pressure and a gas flow of $33 \mathrm{sccm}$ (figure $1(\mathrm{~g})$ ). The morphology and structure of the $\mathrm{W}$ film were investigated by scanning electron microscopy (SEM) (Field Emission LEO 1550) and x-ray diffraction (XRD) (Siemens Kristalloflex 805). The resistivity was measured with a fourpoint probe technique (Tencor OmniMap RS75). The thin-film hardness was determined with an MTS Nano Indenter XP. The residual stress in the $\mathrm{W}$ film was obtained from wafer curvature measurements (Tencor FLX-2900) prior to and after W deposition. Then the backside of the wafer was opened after photolithography by dry etch with the Alcatel 601E, using previously mentioned settings (figure $1(\mathrm{~h})$ ). To define the $\mathrm{W}$ cantilevers, W was structured after photolithography with $50 \mathrm{sccm}$ $\mathrm{SF}_{6}$ at $0.65 \mathrm{~Pa}$ pressure and $800 \mathrm{~W}$ power at an etch rate of $480 \mathrm{~nm} \mathrm{~min}{ }^{-1}$ in an STS Multiplex ICP machine (figure 1(i)). To form the body of the probe, two layers of the negative type photopolymer SU-8 were used. On top of a $10 \mu \mathrm{m}$ thick layer, a $200 \mu \mathrm{m}$ thick layer was applied (figures 1(j) and (k)) using SU-8 MCC-2007 and SU-8 MCC-50, respectively. To obtain a good adhesion between the polymer and the $\mathrm{W}$, the baking settings must be controlled for the first the layer of SU-8. We performed a dehydration of the wafer prior to spinning of the MCC-2007 and after the photolithography a hardbake followed at $115^{\circ} \mathrm{C}$ for $1 \mathrm{~h}$. The two-layered body ensures access to the short cantilevers (down to $27 \mu \mathrm{m}$ ) by the focused laser used for beam deflection sensing. The final release was initiated by a partial etch-through process in a $40 \% \mathrm{KOH}$ solution at $60^{\circ} \mathrm{C}$ at a rate of $\sim 18 \mu \mathrm{m}$ per hour (figure 1(1)) during which the front side of the wafer was protected with a vacuum chuck wafer holder. By using a calibration sample wafer the Si etch rate was measured, which was used to determine the moment when $\sim 10 \mu \mathrm{m}$ of Si was left. From there the etch was closely monitored. Since Si becomes optically transparent when its thickness is below $10 \mu \mathrm{m}$, its degree of transparency was used to stop the etch before reaching the $\mathrm{SiO}_{2}$ membrane, leaving between 2 and $4 \mu \mathrm{m} \mathrm{Si}$. This was done to avoid breaking of the membrane due to its released internal stress in addition to the pressure difference present between the backside of the wafer 


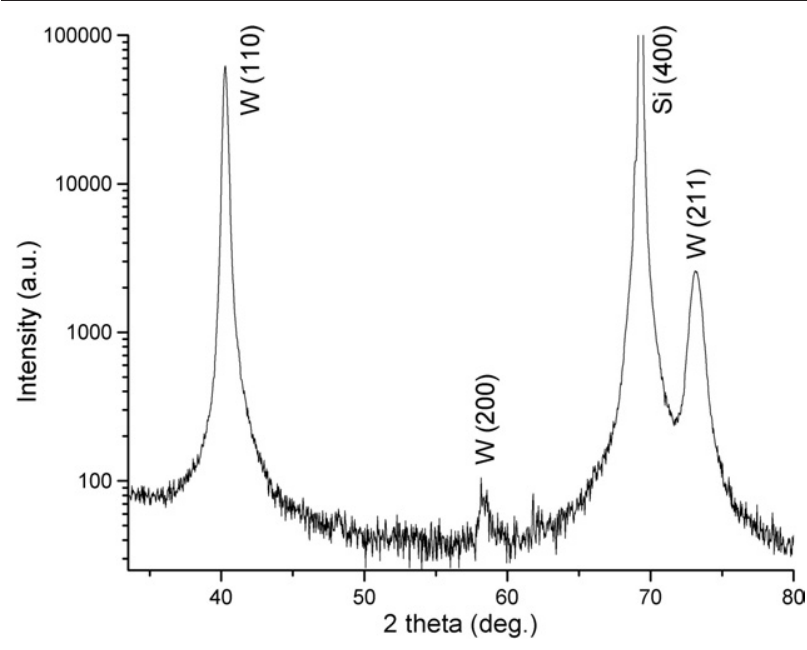

Figure 2. XRD spectrum for an as-deposited $500 \mathrm{~nm}$ thick $\mathrm{W}$ film, showing different peaks associated with $\mathrm{W}$, as well as the (400) peak of the Si wafer.

$\left(P_{\mathrm{KOH}}\right)$ and its front side $\left(P_{\mathrm{atm}}\right)$. Contact of $\mathrm{KOH}$ at the $\mathrm{W}-\mathrm{SU}-$ 8 interface would immediately result in a loss of adhesion. The remaining Si was removed by dry etching in the Alcatel 601E with the oxide serving as an etch stop (figure $1(\mathrm{~m})$ ). Finally the $\mathrm{SiO}_{2}$ membrane was removed in a BHF solution (figure 1(n)). Several $\mathrm{W}$ probe designs were made with different length and width, giving different resonance frequencies and spring constants. Images were obtained in a PSIA XE-100 AFM. The resonance frequencies were measured by laser-interferometry from which the Young's modulus for the W was calculated and $I V$ measurements were performed with a home-built AFM system to measure the contact resistance.

\section{Results and discussion}

After W sputtering deposition, an XRD analysis of the deposited W layer was performed (figure 2) revealing its crystalline nature. The absence of a peak at $35.3^{\circ}$ indicates that no $\beta$-phase $\left(\mathrm{W}_{3} \mathrm{O}\right)$ is present [26] and hence confirms that the $\mathrm{W}$ pre-sputtering for removal of any $\mathrm{WO}_{x}$ was sufficient. The W(110) peak dominates compared to the other W peaks. During growth, the other initially present orientations disappear in favour of the $\mathrm{W}(110)$ orientation, which has the lowest surface energy. SEM inspection of the W surface shows a granular structure of the as-deposited film on top of $500 \mathrm{~nm}$ thermal oxide (figure 3(a)). The typical form and arrangement of these stretched grains is attributed to the W(110) orientations. Figure 3(b) shows the W crosssection of the cleaved film with $20^{\circ}$ of tilt. A columnar structure with a typical width of $100 \mathrm{~nm}$ is observed. The large number of grain boundaries and other defects, such as vacancies, dislocations and impurities, will influence the electrical conductivity of the film. Indeed, four-point probe measurements indicate a specific resistance that is three times higher, $14.8 \times 10^{-6} \Omega \mathrm{cm}$, compared to the bulk value of $5.5 \times 10^{-6} \Omega \mathrm{cm}$ [23]. The measured microhardness of the film is $14 \mathrm{GPa}$, which corresponds to previously reported values $[21,22]$. With wafer curvature measurements before and after $\mathrm{W}$ deposition, the stress $\sigma_{\mathrm{f}}$ in the $\mathrm{W}$ film is obtained
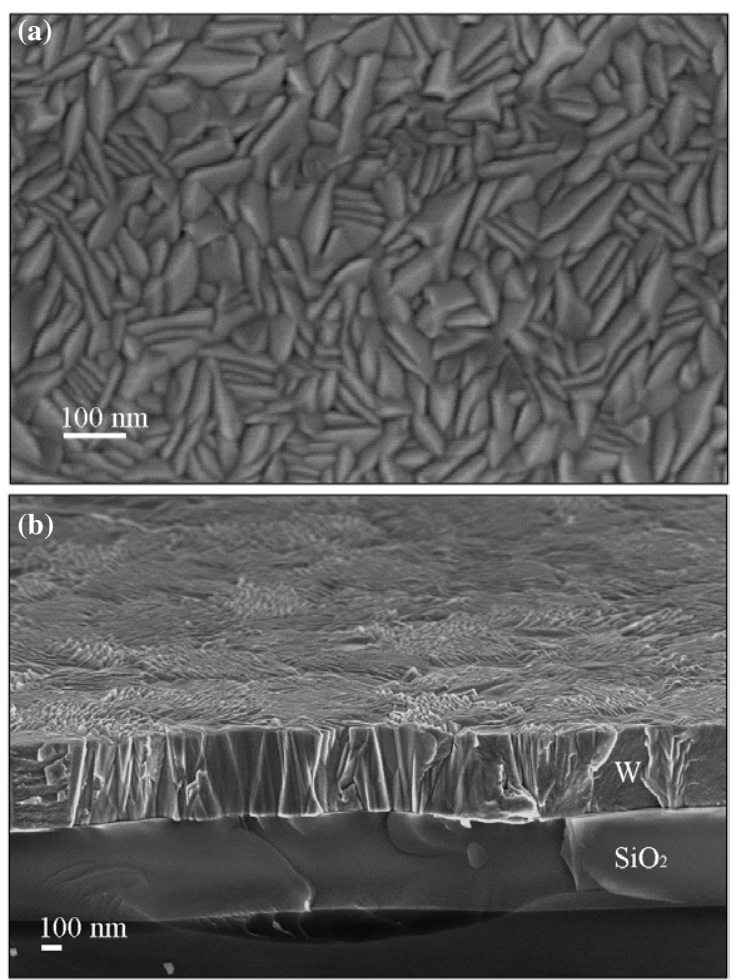

Figure 3. SEM images of the as-deposited tungsten film, with in (a) the $\mathrm{W}$ surface and (b) the W film with a columnar structure in cross section under $20^{\circ}$ of tilt.
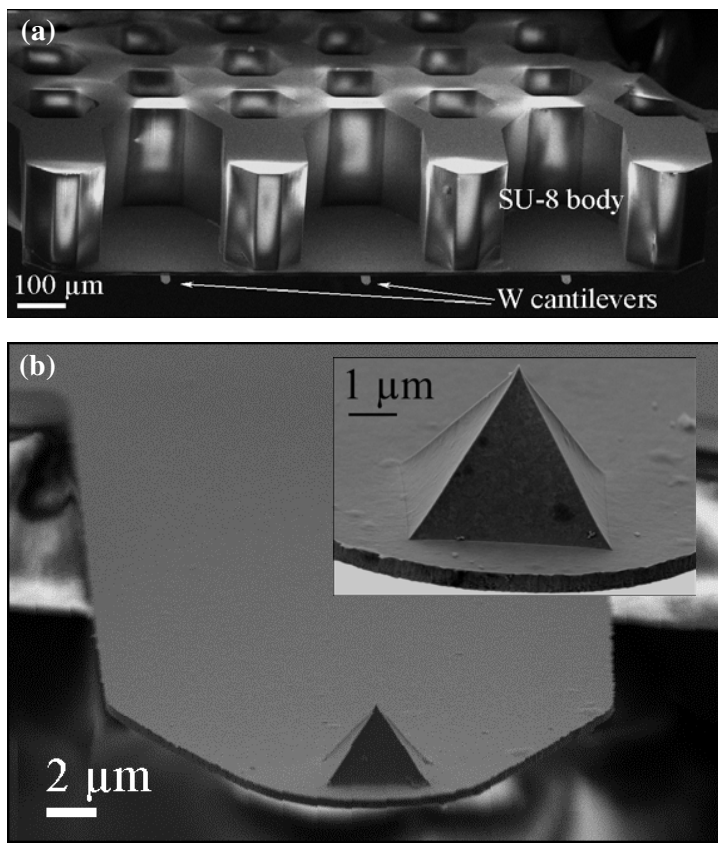

Figure 4. SEM images of the hybrid AFM probe: (a) top view of the probe, with three $\mathrm{W}$ cantilevers of $27 \mu \mathrm{m}$ long, (b) image of a cantilever from the tip-side. Inset: close-up of the tip, with radius of curvature below $20 \mathrm{~nm}$.

using Stoney's equation [27],

$$
\sigma_{\mathrm{f}}=\frac{E_{\mathrm{s}} d_{\mathrm{s}}^{2}}{6 R\left(1-v_{\mathrm{s}}\right) d_{\mathrm{f}}}
$$


Electrically conducting probes with full tungsten cantilever and tip for scanning probe applications
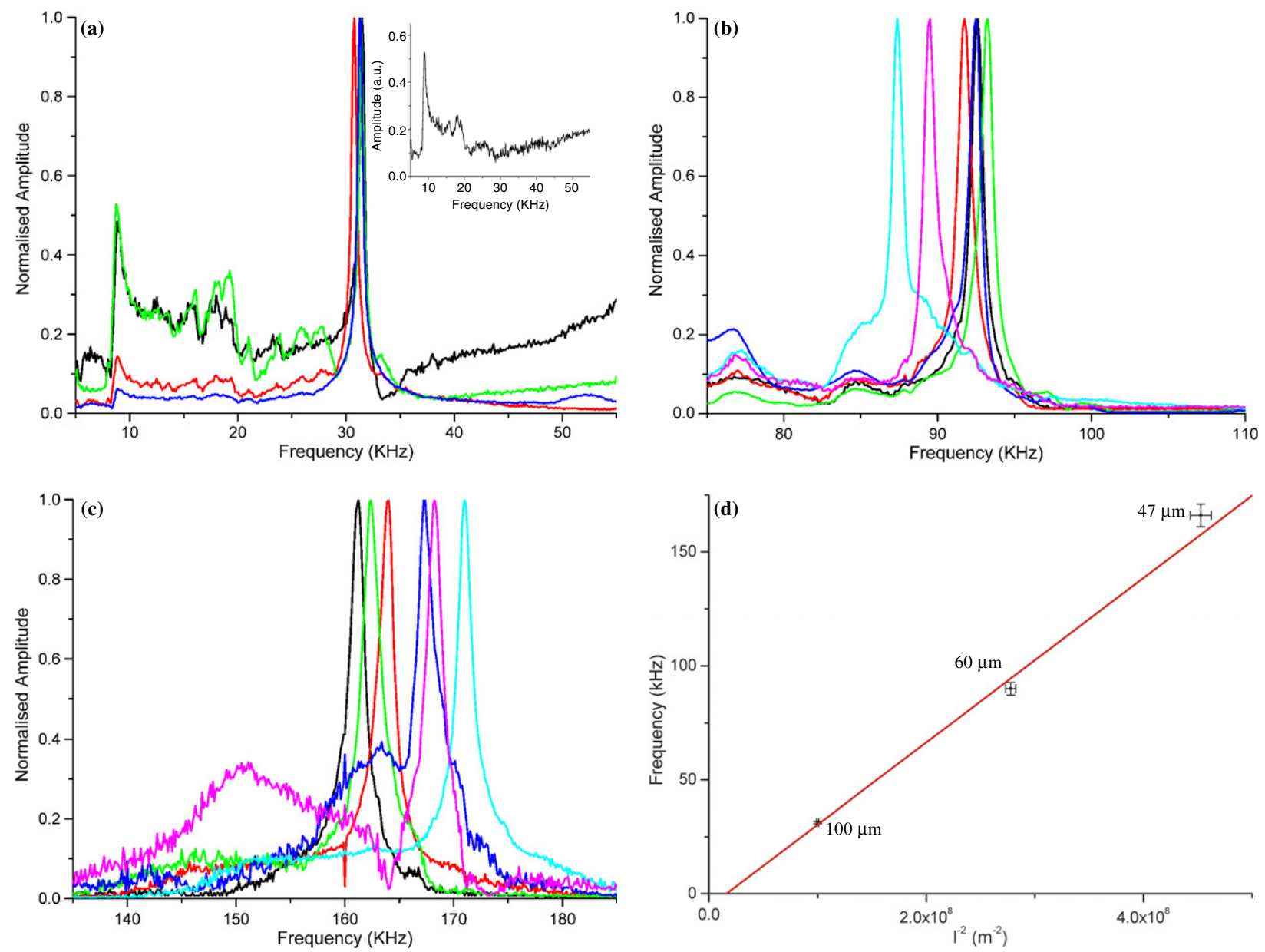

Figure 5. Typical resonance frequency plots for three different types of $\mathrm{W}$ cantilever: (a) $100 \mu \mathrm{m} \times 20 \mu \mathrm{m}$, (b) $60 \mu \mathrm{m} \times 12 \mu \mathrm{m}$ and (c) $47 \mu \mathrm{m} \times 20 \mu \mathrm{m}$. The inset in (a) shows the background signal, which is independent from the actual cantilevers' resonances. Figure 5(d) shows the measured resonance frequencies versus $l^{-2}$. From the slope of the line the W Young's modulus is calculated to be $380 \pm 40 \mathrm{GPa}$.

where $R$ is the radius of curvature, $E_{\mathrm{s}}$ and $v_{\mathrm{s}}$ the substrate's respective Young's modulus and Poisson's ratio, and $d_{\mathrm{s}}$ and $d_{\mathrm{f}}$ the substrate and film thickness, respectively. A residual compressive stress of $600 \mathrm{MPa}$ was calculated. Figure 4 shows SEM images of a finished probe after the fabrication process. Figure 4(a) shows a probe from the topside where the hexagonal structure of the SU-8 body is clearly visible. Three $27 \mu \mathrm{m}$ long cantilevers are attached to the body. From the figure it can be seen how the two-layer SU-8 body was shaped to enable access for the focused laser beam to the cantilevers. Figure 4(b) shows a W cantilever with integrated tip and in the inset the tip with a radius of curvature smaller than $20 \mathrm{~nm}$ is shown. The observed cantilever and tip surface in the figure are smooth, since this side of the $\mathrm{W}$ formed previously the interface with $\mathrm{SiO}_{2}$. The cantilevers were subsequently analysed in a laser interferometry system at ambient conditions. Figures 5(a)(c) show typical normalized zeroth-order resonance frequency plots for three types of cantilever: in respective order of $100 \mu \mathrm{m} \times 20 \mu \mathrm{m}, 60 \mu \mathrm{m} \times 12 \mu \mathrm{m}$ and $47 \mu \mathrm{m} \times 20 \mu \mathrm{m}$. For each type of cantilever several probes were measured and plotted to register their corresponding resonance frequencies. For the $100 \mu \mathrm{m}$ long cantilevers, $f=31.2 \pm 0.5 \mathrm{kHz}$, for the $60 \mu \mathrm{m}$ long ones $f=90 \pm 2.7 \mathrm{kHz}$, and the $47 \mu \mathrm{m}$ long cantilevers show $f=166 \pm 5 \mathrm{kHz}$, which means the same deviation for each type, of about $3 \%$. The zeroth-order resonance frequency for a cantilever of rectangular shape is given by

$$
f=0.162 \frac{t}{l^{2}} \sqrt{\frac{E_{\mathrm{w}}}{\rho_{\mathrm{w}}}}
$$

where $t$ and $l$ are the beam's thickness and length, respectively, $E_{\mathrm{W}}$ is the Young's modulus of $\mathrm{W}$ and $\rho_{\mathrm{W}}$ is its mass density. When we plot $f$ versus $l^{-2}$ (figure 5(d)), the Young's modulus $E_{\mathrm{w}}$ can be determined from the slope of the line. The error $\Delta l$ in $l$ is taken $0.5 \mu \mathrm{m}$ due to misalignment during fabrication, resulting in an error in $l^{-2}$ of $\Delta\left(l^{-2}\right)=2 \Delta l * l^{-3}$. The measured deviations in $f$ are defined as the error $\Delta f$. The corresponding errors are indicated in the graph, giving the corresponding best fit. From the slope of the curve, $E_{\mathrm{w}}$ is determined using equation (2). The bulk value of $\rho_{\mathrm{w}}=$ $19.3 \times 10^{3} \mathrm{~kg} \mathrm{~m}^{-3}$ [23] is used and $t=500 \mathrm{~nm}$, giving $E_{\mathrm{w}}=$ $380 \mathrm{GPa}$. Rewriting equation (2) and taking the corresponding partial differentials, gives for the uncertainty in $E_{\mathrm{w}}$

$$
\Delta E_{\mathrm{w}}=\frac{\rho_{\mathrm{w}}}{(0.162 t)^{2}}\left(2 f l^{4} \Delta f+4 f^{2} l^{3} \Delta l\right) .
$$

This gives $E_{\mathrm{w}}=380 \pm 40 \mathrm{GPa}$ for the $47 \mu \mathrm{m}$ cantilever series. This value compares well with literature bulk values 


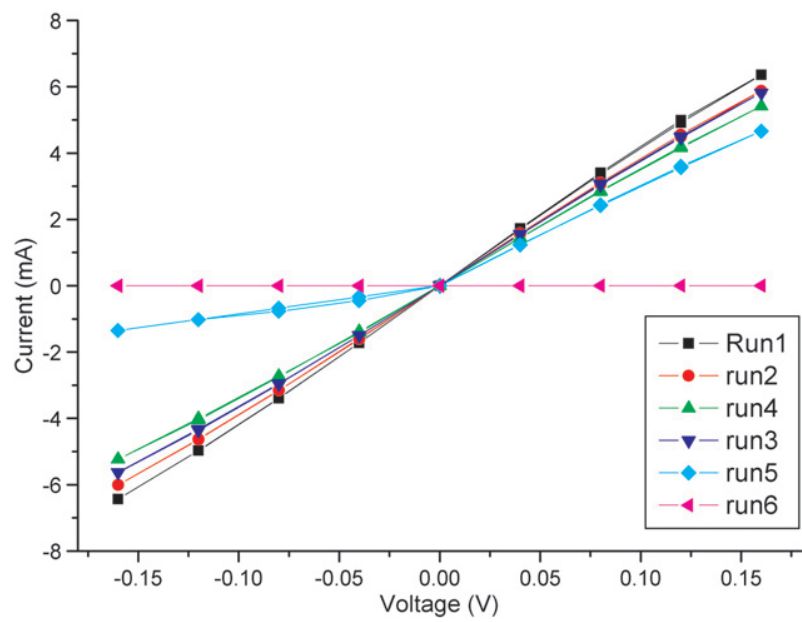

Figure 6. Typical $I V$ plots for analysis of a $\mathrm{W}$ probe under ambient conditions. Six subsequent voltage sweeps with discrete steps of $0.04 \mathrm{~V}$ from 0 to $0.16 \mathrm{~V}, 0.16$ to $-0.16 \mathrm{~V}$ and back from -0.16 to $0 \mathrm{~V}$ are shown. A contact resistance of $25-35 \Omega$ is measured. Due to high current densities the tip eventually oxidizes.

for $E_{\mathrm{w}}$, reported to be between 360 and $405 \mathrm{GPa}[23,28]$ Subsequently, from the graphs in figure 5 the mechanical $Q$ factors (in air) can be determined, giving $Q \cong 46,87$ and 90 for the 100, 60 and $47 \mu \mathrm{m}$ long cantilevers, respectively. Due to the defectuous nature of the $\mathrm{W}$, it is expected that these values are lower than for crystalline Si cantilevers. The contact resistance of the probes was determined in a home-built AFM system equipped with $I V$ mode, by sweeping the voltage and monitoring the current. A gold sample was used to guarantee an oxidation-free sample surface. Figure 6 shows typical $I V$ curves for a W probe (47 $\mu \mathrm{m}$ long with a spring constant of about $2.3 \mathrm{~N} \mathrm{~m}^{-1}$ ) in contact with a force of approximately $100 \mathrm{nN}$, which provides a good physical contact. The voltage was changed in discrete steps of $0.04 \mathrm{~V}$ from 0 to $0.160 \mathrm{~V}$, then from 0.160 to $-0.160 \mathrm{~V}$ and back to $0 \mathrm{~V}$. Each distinct voltage was kept for $200 \mathrm{~ms}$. The measured contact resistance for the first measurement is $25 \Omega$, increasing to $35 \Omega$ at $0.160 \mathrm{~V}$ for the fifth measurement, which is substantially lower than those of B-doped DCL probes or metal-coated probes (respectively $4 \mathrm{k} \Omega$ and $100 \Omega$ ). The curves in the figure are not fully straight but show a third-order dependence, since the resistivity depends on the temperature of the tip. Due to high current densities $\sim 10^{8} \mathrm{~A} \mathrm{~cm}^{-2}$ at maximum voltage, the tip heats up, the $\mathrm{W}$ in the tip locally oxidizes and no more electrical conduction is observed (figure 6, curve 6). Figure 7 shows an AFM image in contact mode of a sample with gold colloids of $100 \mathrm{~nm}$ in diameter. Here, we show the feasibility of our W AFM probes in contact mode, without emphasis on lateral resolution since it is the tip sharpness that determines it. The image was taken with a $27 \mu \mathrm{m}$ long cantilever having a spring constant of $12 \mathrm{~N} \mathrm{~m}^{-1}$ at $1 \mathrm{~Hz}$ scanning frequency and a set point of $100 \mathrm{nN}$ (PSIA XE-100). The simplest AFM images to obtain were with the shortest cantilevers. A residual stress gradient in the $\mathrm{W}$ cantilevers causes slight bending, this effect being more pronounced for the longer cantilevers. This bending causes the reflected laser beam to fall outside the photodetector for sensing the beam deflection, which can therefore not be measured. With straight

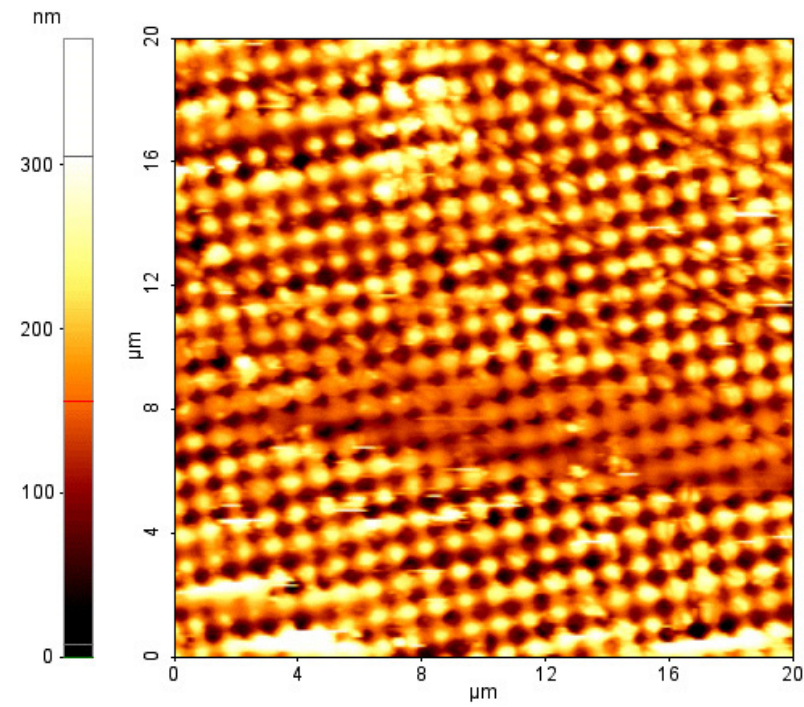

Figure 7. $20 \mu \mathrm{m} \times 20 \mu \mathrm{m}$ AFM image of a sample with gold colloids with a diameter of $100 \mathrm{~nm}$. The $256 \times 256$ points image was taken at $1 \mathrm{~Hz}$ at an approximate setpoint of $100 \mathrm{nN}$ with a $27 \mu \mathrm{m}$ long $\mathrm{W}$ cantilever.

and smoother cantilevers, however, dynamic measurements would have become possible. Thermal annealing of the W during the fabrication process (before structuring the W film) could remove the stress gradient, through two mechanisms: both the crystalline orientations as well as the concentrations of impurities, like incorporated oxygen or trapped water present in the $\mathrm{W}$, change as a function of the deposited layer thickness. Annealing results in the removal of those impurities. Furthermore, the number of grain boundaries, vacancies and dislocations decreases, giving a lower specific resistance, and the $\mathrm{W}$ surface will smoothen, thereby enhancing the reflected laser signal. A drawback is a reduction in hardness due to the increased grain size, though with improved crystallinity the mechanical properties are expected to improve. As mentioned before, additional tip sharpening by means of the FIB $[16,18]$ is possible and would make the probes perform better in dynamic SPM measurements such as KPM, but this is a costintensive method. For experiments in electrical conducting mode one should consider however that an infinite sharp tip is not desired, since this results in a higher contact resistance and corresponding higher heat dissipation. This explains the main limitation of the use of $\mathrm{W}$ probes in electrical conducting mode at ambient conditions, which is their vulnerability to oxidation upon heating. Improvement of inertness forms a next crucial step in the development of electrically conducting probes. From this point it will become interesting to study their long-term stability, for resistance to both wear and oxidation. Addition of nitrogen to the $\mathrm{W}$ could improve the resistance to oxidation. Compounds such as $\mathrm{W}_{x} \mathrm{~N}$ and $\mathrm{WTi}_{x} \mathrm{~N}_{y}$ are possible candidates. If the concentration of nitrogen is kept sufficiently low, the electrical conductivity will still show desired values. Moreover, the hardness will increase significantly. For $\mathrm{W}_{95} \mathrm{~N}_{5}$ with a crystalline W phase a hardness of $37 \mathrm{GPa}$ has been published [19]. Also, the use of a more noble material such as platinum (Pt) is an option, although its hardness is lower. 
Electrically conducting probes with full tungsten cantilever and tip for scanning probe applications

\section{Conclusions and outlook}

A hybrid type of conducting AFM probe with SU-8 body with full $\mathrm{W}$ cantilever and tip has been developed. The probe's tip has a radius below $20 \mathrm{~nm}$ and opens up new opportunities for AFM investigations involving electrically (conducting) measurement modes, in contact mode as in non-contact mode, such as KPM. The measured W thin-film hardness is $14 \mathrm{GPa}$. From the different resonance frequencies the Young's modulus of the W cantilevers is determined: $E_{\mathrm{w}}=380 \pm 40 \mathrm{GPa}$, corresponding to the $\mathrm{W}$ bulk value between 360 and $405 \mathrm{GPa}$. The mechanical $Q$-factors at ambient conditions are up to 90 . The probes show a contact resistance of $25-35 \Omega$ on a $\mathrm{Au}$ sample which is significantly lower than for metal-coated or Bdoped DLC cantilevers. At high current densities the tip heats up, the $\mathrm{W}$ oxidizes locally, and becomes non-conducting. To overcome these oxidation problems the use of a noble metal such as Pt is a good option, but at the cost of tip hardness. Other possibilities are compounds of $\mathrm{W}$, such as $\mathrm{W}_{x} \mathrm{~N}$ or WTiN. The electrical resistivity of these materials is higher, but at the same time the hardness of the tip can be increased from 14 to $37 \mathrm{GPa}$. We believe that these materials will lead the way to the development of an inert wear-resistant electrically conducting AFM probe with nanometric sharp tip and low contact resistance.

\section{Acknowledgments}

This work was financially supported by Hitachi Ltd. The authors thank Carmen Serra from C.A.C.T.I. at the University of Vigo, Spain for the hardness measurement of the W film. We acknowledge the staff of the EPFL Centre of Micro and Nano Technology (CMI) as well as our colleagues from the Microsystems Laboratory for useful discussions and help. We gratefully thank K Pataky of EPFL, Professor R Spolenak of ETH Zürich, Switzerland and Dr Y Goto of Hitachi Ltd for fruitful discussions.

\section{References}

[1] Binnig G, Quate C F and Gerber Ch 1986 Atomic force microscope Phys. Rev. Lett. 56 930-3

[2] Brugger J, Buser R A and de Rooij N F 1992 Silicon cantilevers and tips for scanning force microscopy Sensors Actuators A 34 193-200

[3] Wolter O, Bayer T and Greschner J 1991 Micromachined silicon sensors for scanning force microscopy J. Vac. Sci. Technol. B 9 1353-7

[4] Boisen A, Hansen O and Bouwstra S 1996 AFM probes with directly fabricated tips J. Micromech. Microeng. 6 58-62

[5] Albrecht T R, Akamine S, Carver T E and Quate C F 1990 Microfabrication of cantilever styli for the atomic force microscope J. Vac. Sci. Technol. A 8 3386-96

[6] Reiley T C, Fan T C and Mamin H J 1995 Micromechanical structures for data storage Microelectron. Eng. 27 495-8

[7] Niedermann Ph, Hänni W, Morel D, Perret A, Skinner N, Indermühle $\mathrm{P} F$ and de Rooij N F 1998 CVD diamond probes for nanotechnology Appl. Phys. A 66 S31-4

[8] Kulisch W, Malave A, Lippold G, Scholz W, Mihalcea C and Oesterschulze E 1997 Fabrication of integrated diamond cantilevers with tips for SPM applications Diamond Relat. Mater. 6 907-11
[9] Unno K, Shibata T and Makino E 2001 Micromachining of diamond probes for atomic force microscopy applications Sensors Actuators A 88 247-55

[10] Rasmussen J P, Tang P T, Sander C, Hansena O and Møller P 1997 Fabrication of an all-metal atomic force microscope probe Transducers'97 pp 463-6

[11] Zou J, Wang X, Bullen D, Ryu K, Liu C and Mirkin C A 2004 A mould-and-transfer technology for fabricating scanning probe microscopy probes J. Micromech. Microeng. 14 204-11

[12] Iwata N, Wakayama T and Yamada S 2004 Establishment of basic process to fabricate full GaAs cantilever for scanning probe microscope applications Sensors Actuators A $11126-31$

[13] Genolet G, Brugger J, Despont M, Drechsler U, Vettiger P, de Rooij N F and Anselmetti D 1999 Soft, entirely photoplastic probes for scanning force microscopy Rev. Sci. Instrum. 70 2398-401

[14] Folch A, Wrighton M S and Schmidt M A 1997 Microfabrication of oxidation-sharpened silicon tips on silicon nitride cantilevers for atomic force microscopy J. Micromech. Syst. 6 303-6

[15] Grow R J, Minne S C, Manalis S R and Quate C F 2002 Silicon nitride cantilevers with oxidation-sharpened silicon tips for atomic force microscopy J. Micromech. Syst. 11 317-21

[16] Akiyama K, Eguchi T, An T, Fujikawa Y, Yamada-Takamura Y, Sakurai T and Hasegawa Y 2005 Development of a metal-tip cantilever for noncontact atomic force microscopy Rev. Sci. Instrum. 76033705

[17] Hantschel T, Slesazeck S, Niedermann Ph, Eyben P and Vandervorst W 2001 Integrating diamond pyramids into metal cantilevers and using them as electrical AFM probes Microelectron. Eng. 57/58 749-54

[18] An T, Eguchi T, Akiyama K and Hasegawa Y 2005 Atomically-resolved imaging by frequency-modulation atomic force microscopy using a quartz length-extension resonator Appl. Phys. Lett. 8713314

[19] Giessibl F J, Hembacher S, Herz M, Schiller Ch and Mannhart J 2004 Stability considerations and implementation of cantilevers allowing dynamic force microscopy with optimal resolution: the qPlus sensor Nanotechnology 15 S79-86

[20] Hayakawa J, Ito K, Fujimori M, Heike S, Hashizume T, Steen J, Brugger J and Ohno H 2004 Current-driven switching of exchange biased spin-valve giant magnetoresistive nanopillars using a conducting nanoprobe J. Appl. Phys. 96 3440-2

[21] Louro C and Cavaleiro A 1999 Hardness versus structure in W-Si-N sputtered coatings Surf. Coat. Technol. 116-119 74-80

[22] Fu T, Zhou Z F, Li K Y and Shen Y G 2005 Structure, stress and hardness of sputter deposited nanocomposite W-Si-N coatings Surf. Coat. Technol. 200 2525-30

[23] Boyer H E and Gall T L 1984 Metals Handbook: Desk 7th edn (Metals Park, OH: ASM International)

[24] Kim G M, Kovalgin A, Holleman J and Brugger J 2002 Replication molds having nanometer scale shape control fabricated by means of oxidation and etching J. Nanosci. Nanotechnol. 2 55-9

[25] Lorenz H, Despont M, Fahrni N, LaBianca N, Renaud P and Vettiger P 1997 SU-8: a low-cost negative resist for MEMS J. Micromech. Microeng. 7 121-4

[26] Maillé L, Sant C, Le Paven-Thivet C, Legrand-Buscema C and Garnier P 2003 Structure and morphological study of nanometer $\mathrm{W}$ and $\mathrm{W}_{3} \mathrm{O}$ thin films Thin Solid Films 428 237-41

[27] Stoney G 1909 The tension of metallic films deposited by electrolysis Proc. R. Soc. A 82 172-5

[28] Verkerk G, Broens J B, Kranendonk W, van der Puijl F J, Sikkema J L and Stam C W 1992 BINAS 3rd edn (Groningen: Wolters-Noordhoff) 